\title{
Application of Quadratic Polynomial Model for the Uptake of Iron from Aqueous Solutions by Natural and Modified Egyptian Bentonite
}

\author{
Mostafa Ragab Abukhadra ${ }^{1}$, Moaaz Korany Seliem ${ }^{1}$, Essam Abdel Rahaman Mohamed ${ }^{1}$, \\ Ali Quarny Selim¹, Mahmoud Helmy Mahmoud ${ }^{2}$
}

${ }^{1}$ Geology Department, Faculty of Science, Beni t-Suef University, Beni Suef City, Egypt

${ }^{2}$ Central Labs, Potable Water \& Sanitation Company, Beni-Suef, Egypt

Email address:

Geomostafa89@yahoo.com (M. R. Abukhadra),debakyms@yahoo.com (M. K. Seliem), hassaan69@yahoo.com (E. A. Mohamed), aliselimq@gmail.com (A. Q. Selim),dr_mahmoud.helmy@yahoo.com (M. H. Mahmoud)

\section{To cite this article:}

Mostafa Ragab Abukhadra, Moaaz Korany Seliem, Essam Abdel Rahaman Mohamed, Ali Quarny Selim, Mahmoud Helmy Mahmoud. Application of Quadratic Polynomial Model for the Uptake of Iron from Aqueous Solutions by Natural and Modified Egyptian Bentonite. American Journal of Applied Chemistry. Vol. 3, No. 6, 2015, pp. 179-187. doi: 10.11648/j.ajac.20150306.11

\begin{abstract}
The natural Egyptian bentonite, collected from south El Hammam area, was modified at three different temperatures $100^{\circ} \mathrm{C}, 200^{\circ} \mathrm{C}$ and $300^{\circ} \mathrm{C}$ for $1 \mathrm{~h}$. The raw and modified bentonite samples were characterized by powder X-ray diffraction (XRD), scanning electron microscope (SEM) and BET surface area. The bentonite modified at $100^{\circ} \mathrm{C}$ exhibited more flaky grains with smooth surface and high surface area as compared to the two other modified types. Response surface methodology in conjunction with central composite rotatable design was used in optimizing and modeling the effect of different parameters such as contact time, initial concentration and dose on the removal of iron ions. Second order quadratic polynomial model was selected to represent the removal process. The mathematical equations of quadratic polynomial model were derived from Design Expert Software (Version 6.0.5). The predicted values from the mathematical equations were highly correlated with the experimental results $\left(\mathrm{R}^{2}\right.$ above 0.9$)$ for the required responses in untreated and modified bentonite at $100^{\circ} \mathrm{C}$ for $1 \mathrm{~h}$. 3D and linear graphs were used to understand the effect of the studied variable parameters and the interaction between them. Under the predicted conditions suggested by the quadratic programming, the modified bentonite at $100^{\circ} \mathrm{C}$ is more promising and the removal efficiency could be enhanced to $100 \%$. The quadratic polynomial model could be efficiently applied for the modeling of iron removal from aqueous solutions by bentonite.
\end{abstract}

Keywords: Quadratic Polynomial, Bentonite, Thermal Modification, Heavy Metals

\section{Introduction}

The intensive industries and agriculture activities with rapid expansion in human population in recent years lead to a continuous influx of toxic materials such as heavy metals into water resources causing water pollution. Iron ions in water caught the eyes of many researchers as one of the common heavy metals that cause serious problems specially at higher concentrations $[1,2]$. Iron ions commonly occur in nature mainly in deeper wells with little or without oxygen [3]. They may occur in dissolved forms as single ions $\left(\mathrm{Fe}^{2+}\right)$ or in undissolved forms as $\mathrm{Fe}(\mathrm{OH})_{3}$ [2]. Sources of iron in water are related to, weathering of iron bearing minerals, dissolving of them from soil toward groundwater, industrial effluents, landfill leakages, acid mine drainage, pipeline corrosion, engine parts and galvanized pipe processes $[4,5$, 6]. The Presence of iron ions with high concentrations has side effects on the water quality and human health $[7,8]$. For example, oxidation of Fe (II) leads to the formation of hydroxide suspensions with unpleasant color, taste and turbidity $[9,10]$. Concerning health problems, iron ions can be precipitated as insoluble $\mathrm{Fe}^{3}$ hydroxide forming toxic derivative in human body which cause some diseases such as neoplasia, cardiomyopathy, arthropathy, anorexia, oliguria and biphasic shock $[11,12]$. According to the World Health Organization (WHO), $0.3 \mathrm{mg} / \mathrm{L}$ is the maximum permissible limit of dissolved iron in drinking water [13], while a concentration of $0.2 \mathrm{mg} / \mathrm{L}$ is the accepted limit according to the European Union [14]. 
Several methods have been applied to remove iron from water including, oxidation [15], ion exchange/solvent extraction [2], membrane separation [16], reverse osmosis, electro dialysis [17]. The adsorption by low cost and effective materials appears to be more promising and strongly recommended for the removal of metal ions from wastewater [17]. Several materials have been investigated as adsorbents for heavy metals such as natural zeolite [18], activated carbon [19], fly ash [20], Bentonite [8, 21, 22], and synthetic zeolite Y [23].

Bentonite as one of the most abundant and available clays is characterized by low cost, high adsorption capacity, small particle size, high porosity, high surface area and high cation exchange capacity. Therefore, Bentonite is one of the most efficient adsorbent for removal of heavy metals from waste water [24, 25]. Bentonite is composed essentially of clay minerals of smectite group, about $80 \%$ smectite clay minerals and smaller amounts of other clay minerals as kaolinite or non-clay minerals as quartz [26]. The smectite group composed of one octahedral sheet between two silica sheets $(2: 1),[27]$ and these layers are held together by Van der Waals forces. One of the most promising and abundant types of smectite group in bentonite is montmorillonite. There are two types of montmorillonite, Na- montmorillonite and $\mathrm{Ca}$ montmorillonite [28, 29]. Na-Montmorillonite characterize by high adsorption, absorption and swelling capabilities as compared to Ca-montmorillonite [30].

The modification of clay minerals has been applied recently [31]. There are several methods for bentonite modifications, such as acid activation, thermal activation and cationic surfactant [32, 33]. Such activation processes resulted in obvious modifications in the physical structures and the chemical properties of bentonite to maximize the adsorption capacity [34, 35]. Thermal modification involves calcination of bentonite at high temperatures, which enhances its surface area, pore volume and total porosity [33].

Recently, Response Surface Methodology (RSM) in experimental design has attracted the attention of many researchers. It is an effective statistical technique which used to determine the optimum operational conditions for the process or to determine a region that satisfies the operating specifications [36]. RSM commonly used to reduce the number of experiments, improve the product from predicted property values and its ability to predict the interactions of more than two or more factors (interactive effects) and effects due to collective contributions of the measured response [37, 38]. The experimental design techniques commonly used for process analysis and modeling are the full factorial, partial factorial and central composite rotatable designs. Central composite rotatable design (CCRD) has been shown to be sufficient to describe the majority of steady-state process responses [39, 40].

Egypt is blessed with 63 million tons of bentonite as a geological reserve [41]. They are distributed in several localities such as El Fayoum area and Western Desert [42, 43]. Unfortunately, little works have been done for the evaluation of such deposits as adsorbent materials for water remediation. Therefore, the aims of this work are: 1) to use the natural and thermally treated Egyptian bentonite in the uptake of iron from aqueous solution, 2) to apply the Response Surface Methodology (RSM) and statistical Central Composite Rotatable Design (CCRD) to evaluate the interactive effect of the selected parameters, 3) to obtain the ideal optimum conditions for maximum removal of iron from aqueous solution by Egyptian bentonite and its thermally modified products.

\section{Experimental Work}

\subsection{Materials}

The starting bentonite samples were collected from bentonite quarry, south of El Hammam city, Northern Western Desert, Egypt. The samples were ground and sieved by $70 \mu \mathrm{m}$ sieve. Then three samples (each sample $15 \mathrm{gm}$ ) from the ground bentonite were prepared to thermal activation. Thermally activated bentonite was prepared by calcination of bentonite in digital electric muffle furnace at $100^{\circ} \mathrm{C}, 200^{\circ} \mathrm{C}$ and $300^{\circ} \mathrm{C}$ for $1 \mathrm{~h}$.

\subsection{Characterization}

X-ray powder diffraction pattern for the bentonite sample and the thermally modified products were obtained using a Philips APD-3720 diffractometer with $\mathrm{Cu} \mathrm{K \alpha}$ radiation, operated at $20 \mathrm{~mA}$ and $40 \mathrm{kV}$ in the $2 \theta$ range of 5-70 at a scanning speed of $5 \% \mathrm{~min}$. The morphology of the bentonite samples and its thermally modified products was studied by scanning electron microscopy using a field emission scanning electron microscope (JSM-6510, JEOL, and Tokyo, Japan). Specific surface area for the raw and modified bentonite was measured by BET method.

\subsection{Adsorption Experiments}

Response surface and central composite rotatable design of quadratic model was designed for three selected parameters (Contact time, initial concentration and the amount of bentonite) to detect the optimum conditions for the removal of iron by Egyptian bentonite and its thermally modified form. The thermally modified product was selected based on the characterization results.

The $\mathrm{pH}$ value fixed at 4 for the experimental runs and adjusted using sodium hydroxide solution $(0.1 \mathrm{~N})$ and nitric acid solution $(0.1 \mathrm{~N}) . \mathrm{pH}$ is selected to be acidic as alkaline $\mathrm{pH}$ above 7 resulted in precipitation of iron hydroxide [3]. The upper and lower limits for the selected variables in the actual and coded values set in (Table 1). Iron stock solutions were prepared by dilution of standard iron solutions (1000ppm) delivered from Sigma Aldrich Company, Egypt.

The experiments were performed according to the tests suggested by the statistical design where $100 \mathrm{ml}$ from the prepared solutions were shaken by orbital shaker with the suggested dosage for various contact times. At the end of each time interval, the adsorbent was removed by filtration using What man $45 \mu \mathrm{m}$ pore size filter paper. Then, the 
filtrate solutions are analyzed by inductively coupled plasma mass spectrometry (ICP-MS). The $\mathrm{pH}$ values for the filtrate solutions re-adjusted to the normal starting value by dilute nitric acid.

Table 1. The level and range of independent variables chosen for removal of iron from aqueous solution.

\begin{tabular}{llllll}
\hline Factor & Name & $\begin{array}{l}\text { Low } \\
\text { actual }\end{array}$ & $\begin{array}{l}\text { High } \\
\text { actual }\end{array}$ & $\begin{array}{l}\text { Low } \\
\text { coded }\end{array}$ & $\begin{array}{l}\text { High } \\
\text { coded }\end{array}$ \\
\hline A & Contact time & $15 \mathrm{~min}$ & $120 \mathrm{~min}$ & -1 & 1 \\
$\mathrm{~B}$ & Fe conc., & $100 \mathrm{ppm}$ & $250 \mathrm{ppm}$ & -1 & 1 \\
$\mathrm{C}$ & Dosage & $0.2 \mathrm{~g}$ & $1 \mathrm{~g}$ & -1 & 1 \\
\hline
\end{tabular}

The removal efficiency was calculated as follows:

$$
\text { Removal efficiency }(\%)=\frac{100\left(C_{0}-C_{e}\right)}{C_{0}}
$$

Where $\mathrm{C}_{0}$ and $\mathrm{C}_{\mathrm{e}}$ are the iron concentrations in the initial solution and the solution after equilibration of iron ions, respectively. $\mathrm{V}$ is the volume of solution in $(\mathrm{ml})$ and $m$ is the mass of sorbent $(\mathrm{g})$. The data obtained were fitted to a second-order polynomial equation:

$$
\mathrm{Y}=\beta_{\mathrm{o}}+\sum_{i=1}^{4} \beta_{i} X_{i}+\sum_{i=1}^{4} \beta_{i i} X_{i}^{2}+\sum_{i=1}^{3} \sum_{j=i+1}^{4} \beta_{i j} X_{i} X_{j} .
$$

Where $\mathrm{Y}$ is the required responses (the removal efficiency of iron (\%)); $\beta_{0}, \beta_{\mathrm{i}}, \beta_{\mathrm{ii}}, \beta_{\mathrm{ij}}$ are constant coefficients $\mathrm{X}_{\mathrm{i}}$ are the uncoded independent variables. Subsequent regression analyses, analyses of variance (ANOVA) and response surfaces were performed using the Design Expert Software (Version 6.0.5). Optimal reaction parameters for maximum removal were generated using the software's numerical optimization function.

\section{Results and Discussion}

\subsection{Characterization of Bentonite}

X-ray diffraction patterns of the original bentonite and its modified products are shown in (Figure 1). It is clear that the original bentonite sample composed mainly of Namontmorillonite with little amounts of kaolinite, quartz and calcite. Na- montmorillonite shows sharp and intensive peak reflecting high d-spacing (13.48 $\AA$, Fig.1). The thermal treatment process has no effect on the present phases and the main effect of it appears on the intensity of the main peak of montmorillonite and the d-spacing values. Bentonite treated at $100^{\circ} \mathrm{C}$ shows no change in the $\mathrm{d}$-spacing value of the main peak of montmorillonite while bentonite samples heated at $200^{\circ} \mathrm{C}$ and $300^{\circ} \mathrm{C}$ show collapse in the crystal structure and this appear in the reduction of the intensity of montmorillonite main peak and the d-spacing to $11.26 \AA$ and $10.15 \AA$ for those treated at 200 and $300^{\circ} \mathrm{C}$ respectively.

Figure 2 shows the SEM images of original bentonite sample and its thermally modified products. Raw bentonite appears in the form of dense aggregates clump, its surface is characterized by the presences of very fine lumps that may be related to the associated mineral impurities (Figure 2A).
After treatment at $100^{\circ} \mathrm{C}$, the resulted modified product appear to be more flaky grains with smooth surface that could be related to the removal of water moistures and other impurities attached to the surface of raw bentonite (Figure 2B) [32]. After $300^{\circ} \mathrm{C}$, the modified product appears to be slightly agglomerated aggregates (Figure 2C), that attributed to collapse of the interlayer space which resulted in tightly bound structure [34].

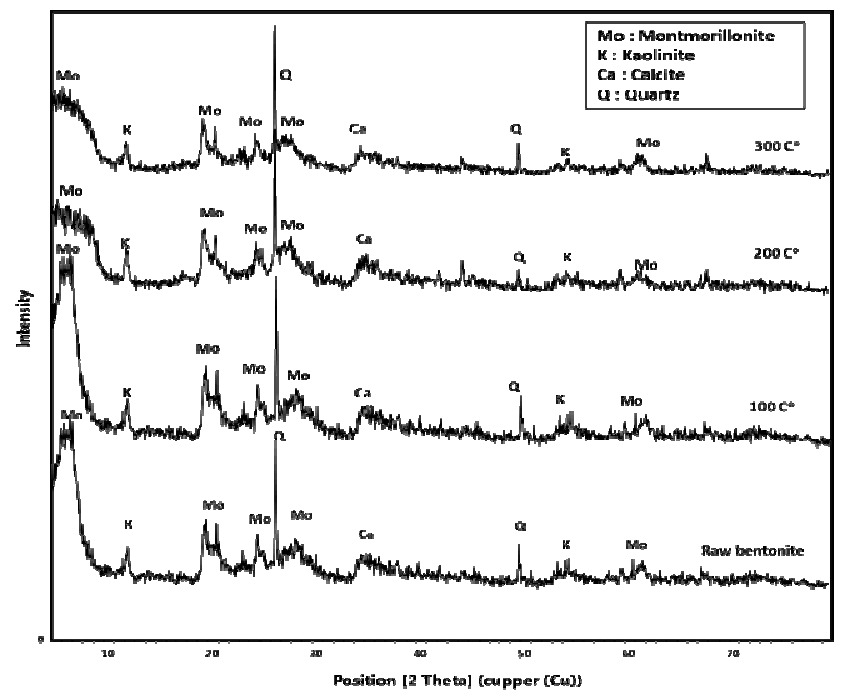

Figure 1. XRD pattern of original Egyptian bentonite and its thermally modified products.

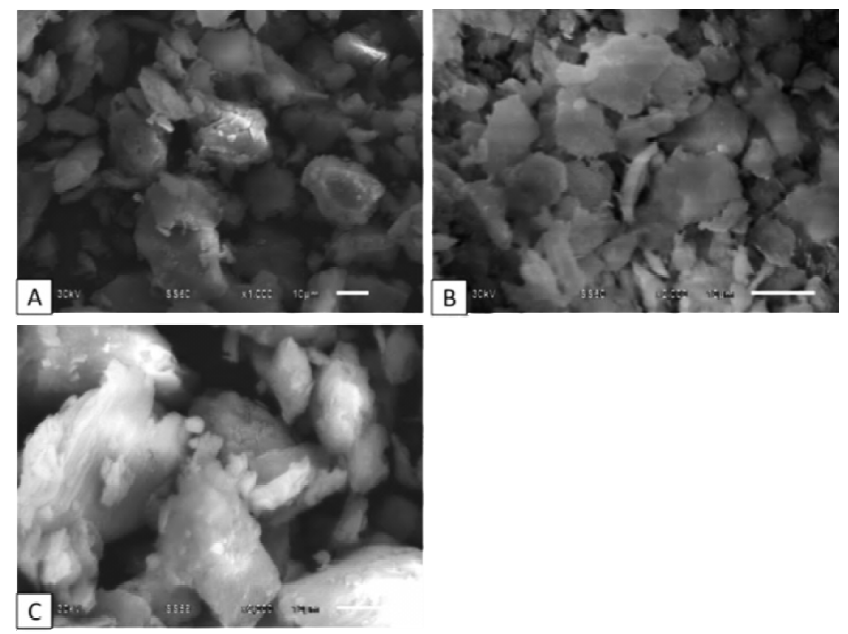

Figure 2. SEM images of (A) original Egyptian bentonite, (B) modified after $100 C^{\circ},(C)$ modified after $300^{\circ} \mathrm{C}$.

The variation in the specific surface area (SSA) with increasing the temperature was shown in (Figure 3). It is clear that the SSA area of raw bentonite gave a value of 27 $\mathrm{m}^{2} / \mathrm{g}$ and this value increased to $35 \mathrm{~m}^{2} / \mathrm{g}$ after treatment at $100^{\circ} \mathrm{C}$ for $1 \mathrm{~h}$. On the other hand, SSA gave values of 22 $\mathrm{m}^{2} / \mathrm{g}$ and $18 \mathrm{~m}^{2} / \mathrm{g}$ for modified bentonite products heated at $200^{\circ} \mathrm{C}$ and $300^{\circ} \mathrm{C}$, respectively. Increasing the surface area after calcination at $100^{\circ} \mathrm{C}$ is attributed to the fact that, the hydroxylation stage involves removal of impurities, adsorbed water and hydrated water attached to the surface of clay which results in weight loss and in turn increasing in the SSA 
[44]. Collapse of the structure after calcination at $200^{\circ} \mathrm{C}$ and $300^{\circ} \mathrm{C}$ bring clay particles close each other which reduce the surface area [45].

\subsection{Adsorption Results}

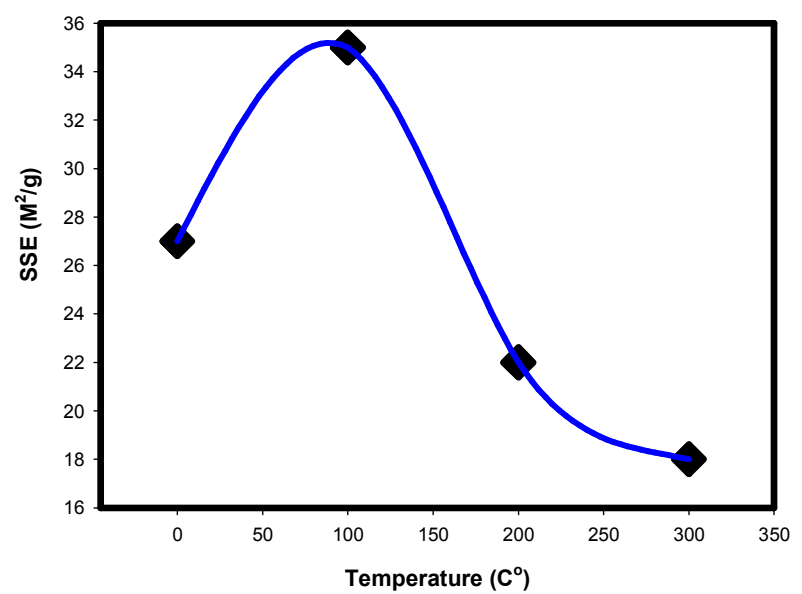

Figure 3. Variation in the SSE with increasing temperature, $\left(0^{\circ} \mathrm{C}\right.$ refer to bentonite at room temperature).

Table 2 summarizes the experimental runs designed with the CCRD for removal of iron from aqueous solution using raw bentonite and thermally modified product at $100^{\circ} \mathrm{C}$ and the resulted responses (The removal efficiency (\%)). The resulted data under optimum experimental conditions (15 minute of contact time, $100 \mathrm{ppm}$ of initial iron concentration and $1 \mathrm{~g}$ of a dose) the maximum percentage of iron removal (\%) are $95 \%$ and $98 \%$ for raw and treated bentonite. The interaction between the selected variables in addition to their effects on different responses is further illustrated.

\subsubsection{Fitness of the Statistical Model}

Second order quadratic polynomial model was selected to represent the relations between the selected parameters and the required responses. Model F-values for the required responses were obtained from the analysis of variance (ANOVA). For the raw bentonite and treated bentonite, the models F-values were 45.57 and 47.5 for the removal of iron \%, respectively. According to the F-values, the model is highly significant with only a $0.01 \%$ noise. Pure errors are zero which indicates very good reproducibility of the obtained data. The mathematical equations of the quadratic polynomial model, which represent the relations between the required responses (removal efficiency of iron \% (Y)) and the selected variables, were obtained from Design Expert Software (Version 6.0.5) for coded units as follows:

For raw bentonite

$$
\begin{gathered}
\mathrm{Y}=+63.63-0.24 \mathrm{XA}-8.15 \mathrm{XB}+30.99 \mathrm{X} \mathrm{C}-8.63 \mathrm{X} \\
\mathrm{A}^{2}+11.03 \mathrm{XB}^{2}-9.87 \mathrm{X} \mathrm{C}^{2}+0.21 \mathrm{XAX} \mathrm{X}-0.51 \mathrm{X}
\end{gathered}
$$

A X C-1.10 X B X C

For thermally modified bentonite

$$
\begin{aligned}
& \mathrm{Y}=+68.46-0.53 \mathrm{XA}-8.73 \mathrm{X} \mathrm{B}+30.73 \mathrm{X} \mathrm{C}-9.99 \mathrm{X} \\
& \mathrm{A}^{2}+13.03 \mathrm{X} \mathrm{B}^{2}-9.0 \mathrm{X} \mathrm{C}^{2}+0.47 \mathrm{XAX} \mathrm{X}-0.31 \mathrm{X}
\end{aligned}
$$

\begin{tabular}{|c|c|c|c|c|c|}
\hline & Variables & & & Raw & Treated \\
\hline Run & A. Contact time (min) & B. Initial concentration (ppm) & C. Dose (g) & Removal of iron, $\%$ & Removal of iron, $\%$ \\
\hline 1 & 15.00 & 100.00 & 1.00 & 95 & 98 \\
\hline 2 & 120.00 & 250.00 & 1.00 & 76 & 84.8 \\
\hline 3 & 60.00 & 100.00 & 0.60 & 88 & 96 \\
\hline 4 & 15.00 & 100.00 & 0.20 & 32 & 43 \\
\hline 5 & 60.00 & 175.00 & 1.00 & 92.5 & 97.14 \\
\hline 6 & 60.00 & 175.00 & 0.20 & 21.7 & 28 \\
\hline 7 & 15.00 & 250.00 & 1.00 & 76.8 & 86 \\
\hline 8 & 120.00 & 100.00 & 0.20 & 32 & 41 \\
\hline 9 & 15.00 & 250.00 & 0.20 & 18.8 & 21.2 \\
\hline 10 & 15.00 & 175.00 & 0.60 & 58.3 & 62.85 \\
\hline 11 & 60.00 & 250.00 & 0.60 & 50 & 59 \\
\hline 12 & 120.00 & 100.00 & 1.00 & 93 & 99 \\
\hline 13 & 60.00 & 175.00 & 0.60 & 58.85 & 64 \\
\hline 14 & 120.00 & 175.00 & 0.60 & 58.7 & 60.57 \\
\hline 15 & 120.00 & 250.00 & 0.20 & 18.8 & 22.4 \\
\hline 16 & 60.00 & 175.00 & 0.60 & 58.85 & 64 \\
\hline
\end{tabular}

$$
\mathrm{A} \mathrm{X} \mathrm{C}+2.03 \text { X B X C }
$$

Table 2. Results of the experimental runs designed according to the CCRD.

Results obtained by the experimental tests and the predicted results obtained using the model equations are given in Table 3 . The predicted results show great agreement with the actual results with high determination coefficient $\left(\mathrm{R}^{2}>0.9\right)$ for the required responses and for the both bentonite samples (Figure 4). This gave an indication about the significance of the quadratic polynomial model and its suitability to represent the actual relations between the required responses and the selected variables. 
Table 3. The predicted and observed values results from the treatment processes.

\begin{tabular}{|c|c|c|c|}
\hline \multicolumn{2}{|c|}{ Natural } & \multicolumn{2}{|c|}{ Thermally treated } \\
\hline \multicolumn{2}{|c|}{ Removal efficiency (\%) } & \multicolumn{2}{|c|}{ Removal efficiency (\%) } \\
\hline actual & Predicted & actual & Predicted \\
\hline 32.00 & 32.19 & 43.00 & 44.30 \\
\hline 32.00 & 32.29 & 41.00 & 42.93 \\
\hline 18.80 & 17.65 & 21.20 & 19.23 \\
\hline 18.80 & 18.61 & 22.40 & 19.51 \\
\hline 95.00 & 97.37 & 98.00 & 102.73 \\
\hline 93.00 & 95.45 & 99.00 & 101.13 \\
\hline 76.80 & 78.43 & 86.00 & 84.75 \\
\hline 76.00 & 77.37 & 84.80 & 84.82 \\
\hline 58.30 & 55.26 & 62.85 & 60.03 \\
\hline 58.70 & 54.78 & 60.57 & 59.38 \\
\hline 88.00 & 82.70 & 96.00 & 85.90 \\
\hline 68.00 & 66.33 & 59.00 & 65.09 \\
\hline 21.70 & 22.56 & 28.00 & 29.63 \\
\hline 92.50 & 84.68 & 97.14 & 91.51 \\
\hline 58.85 & 63.49 & 64.00 & 66.67 \\
\hline 58.85 & 63.49 & 64.00 & 66.67 \\
\hline
\end{tabular}

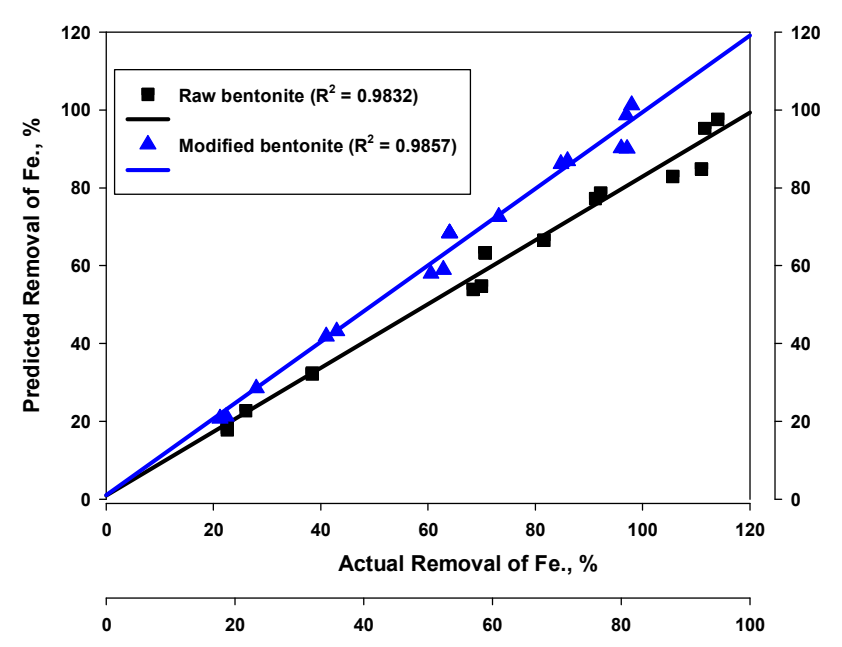

Figure 4. $R^{2}$ values for the removal efficiency of iron (\%) for raw and modified bentonite.

\subsubsection{Effect of Interaction Between Operating Parameters}

Effect of the selected parameters on the removal of iron by raw and thermally modified bentonite as well as the interaction effect between them was expressed in linear and $3 \mathrm{D}$ response surface diagrams. Response surface plots in terms of two selected factors at any one time maintaining all other factors at fixed levels are suitable in understanding either the main or the interaction effects of these two factors and represented by 3D diagrams. The elliptical shape of the curve indicates good interaction of the two variables and circular shape indicates no interaction between the variables [46].

\section{(i). Interaction Between Contact Time and Dosage}

Figure 5. A and B shows 3D diagrams for the interaction between the contact time and dosage of natural and thermally modified bentonite. Plotting the interaction between the contact time and dosage values was performed at central fixed initial concentrations of iron (175 ppm) and fixed $\mathrm{pH}$ (4).

At any applied dose, the removal efficiency increased with increasing the contact time from 15 to $60 \mathrm{~min}$ and then the removal efficiency appear to be fixed after 60 minute. The previous behavior is fixed at the natural and thermally modified bentonite. This is related to the availability of sorption sites from $15 \mathrm{~min}$ to $60 \mathrm{~min}$. With increasing time, the number of such active sites reduced indicating the adsorption capacity was nearly constant [47].

The interaction effect of contact time at different applied masses appeared in the increase of the removal efficiency with the dose at any given time. For example at fixed time (60 $\mathrm{min}$ ) the removal value increased from $21.7 \%$ to about 92.5 for raw bentonite by increasing the bentonite dose from $0.2 \mathrm{~g}$ to $1 \mathrm{~g}$. Under the same conditions, the removal value increased from $28 \%$ to $97.14 \%$ for the treated bentonite. Increasing the adsorption capacity with increasing the amount of bentonite is related to the increase in the total surface area of the adsorbent particles and the available sorption active sites [48, 49].

Thermally modified bentonite gave high efficiency in the removal of iron under the same conditions and at any given contact time (Figure 6). Therefore, thermally treated bentonite at $100{ }^{\circ} \mathrm{C}$ for $1 \mathrm{~h}$ is promising for the uptake of iron from water.

\section{(ii). Interaction Between Contact Time and Initial Iron Concentration}

The interaction effect between the contact time and the initial iron concentration is represented by $3 \mathrm{D}$ response surface diagram for the raw and modified bentonite (Fig. 7.A and $\mathrm{B}$ ). The interaction relation was investigated at central fixed $\mathrm{pH} 4$ and dosage $0.6 \mathrm{gm}$.

The removal efficiency decrease with increasing the initial iron concentration at any given time as shown in the response surface plotting and this trend fixed in both raw bentonite and thermally modified one. Higher adsorption capacity at lower iron concentration is attributed to availability of active sorption sites at lower concentrations, while increasing the initial iron concentrations provide more iron ions, however the fixed amount from the used adsorbent has a fixed number of sorption sites $[46,50]$.

Contact time of $60 \mathrm{~min}$ still the optimum experimental time for maximum removal of iron at different initial concentrations.

Interaction effect of contact time at different iron concentrations was given in (Figure 7). The removal efficiency for raw bentonite at fixed time and dose $(60 \mathrm{~min}$ and $0.6 \mathrm{~g}$ ) decreased from $88 \%$ to $68 \%$ by increasing the initial concentration from $100 \mathrm{ppm}$ to $250 \mathrm{ppm}$ (Figure 7A). Under the same conditions, the removal value decreased from $96 \%$ to $73.2 \%$ for the treated bentonite (Figure $7 \mathrm{~B}$ ).

Therefore, thermally modified bentonite still has the high separation efficiency at all applied concentrations of iron in the solutions and at any given time (Figure 8). 


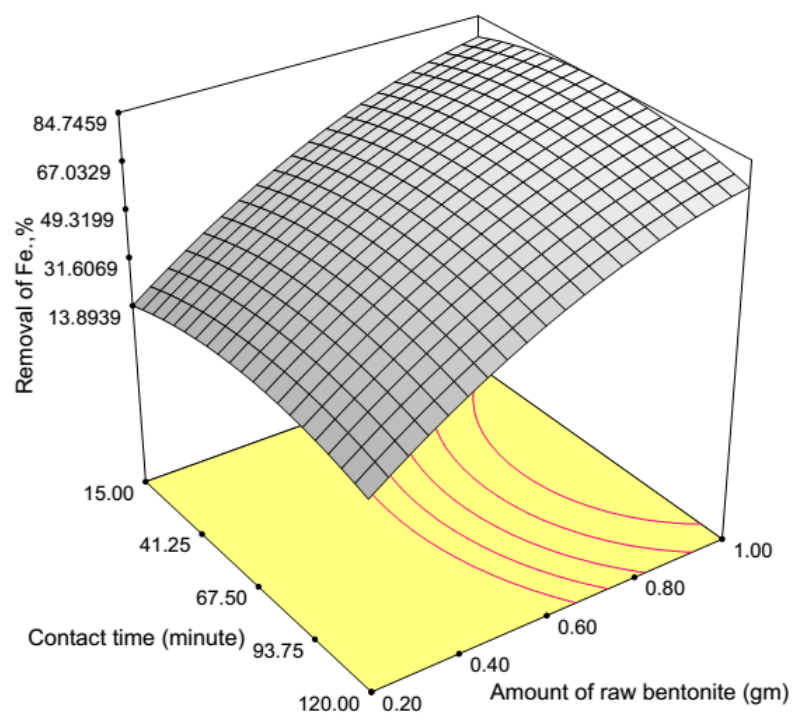

(A)

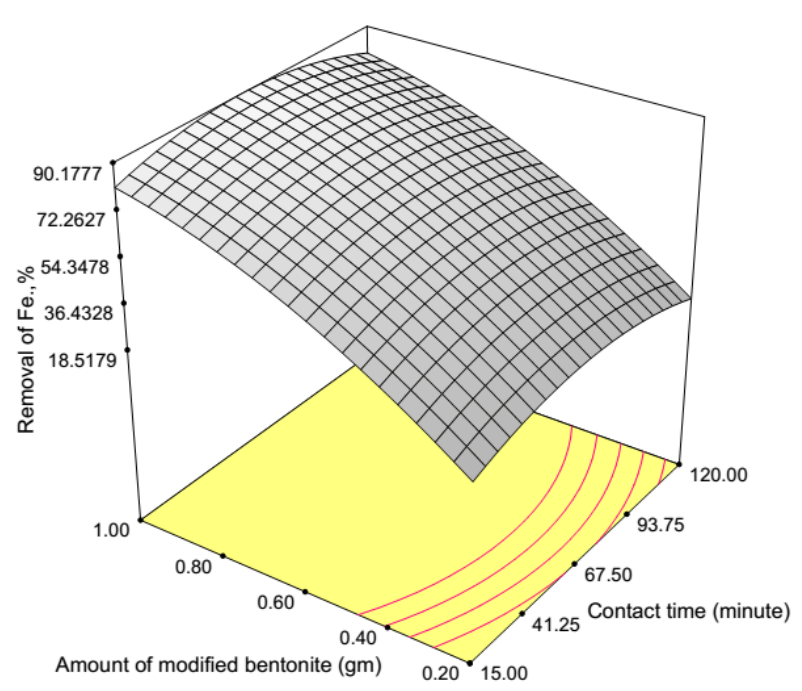

(B)

Figure 5. Interaction effect between contact time and dose on the required responses (A) Raw bentonite (B) Thermally modified bentonite.

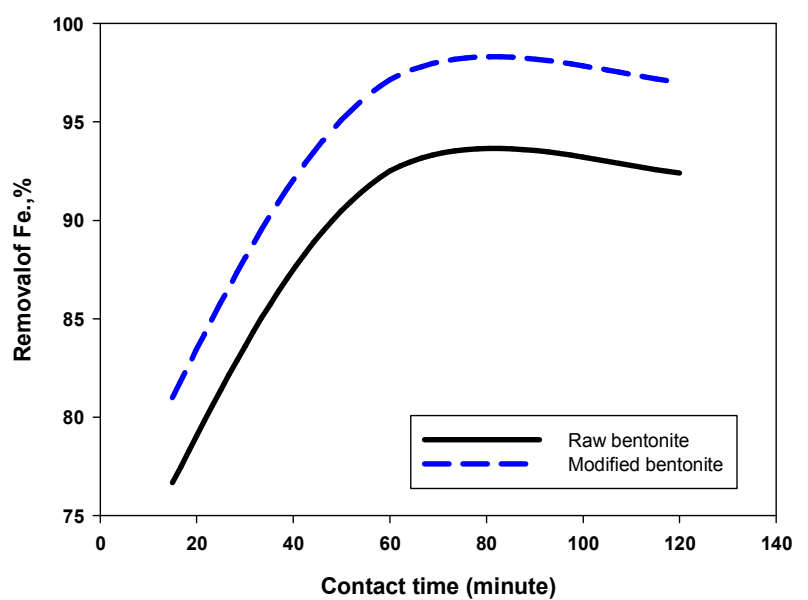

Figure 6. Differences in the removal of Fe., \% between natural and modified bentonite with time at the optimum dose: $\operatorname{lgm}(\mathrm{PH}: 4$, Initial concentration :175 ppm).

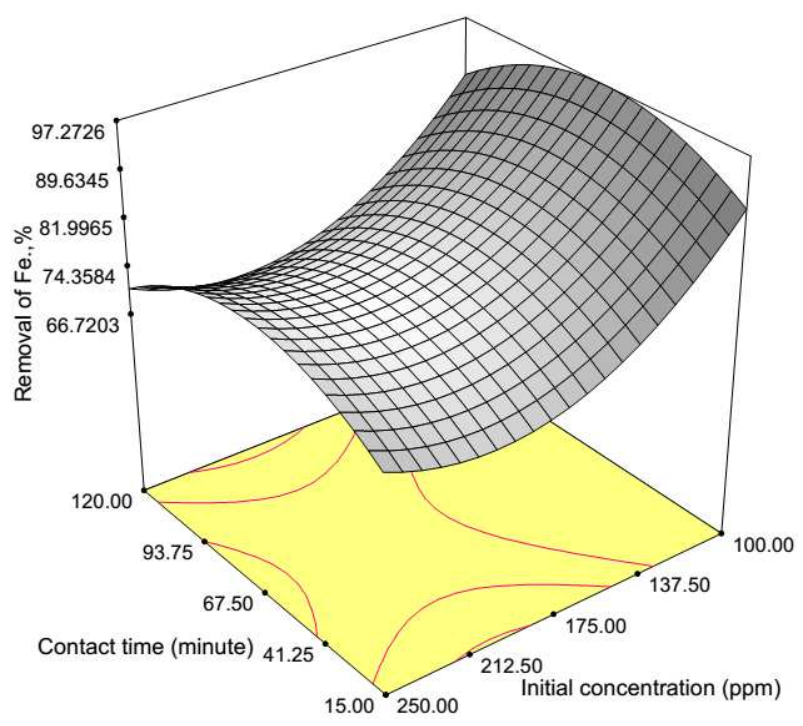

(A)

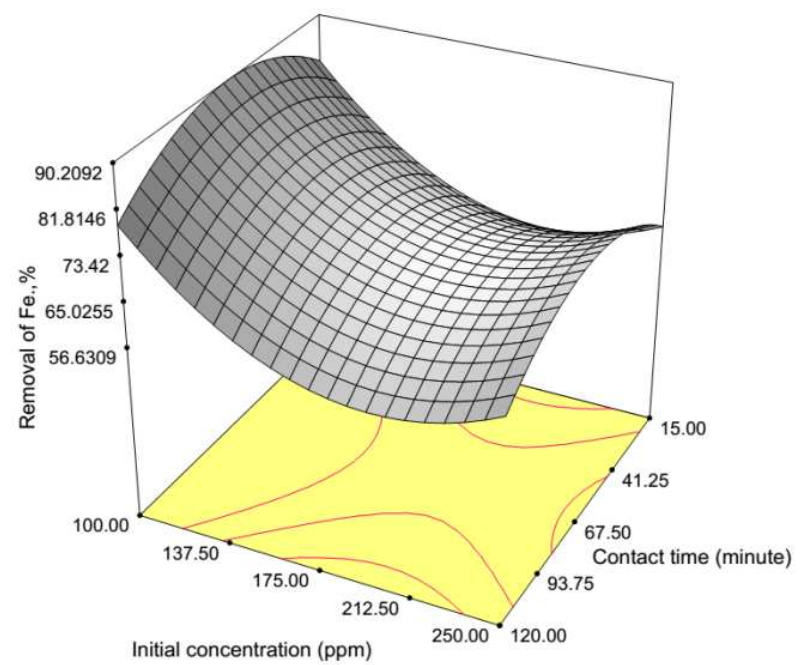

(B)

Figure 7. Interaction effect between contact time and initial iron concentration (A) Raw bentonite (B) Thermally modified bentonite.

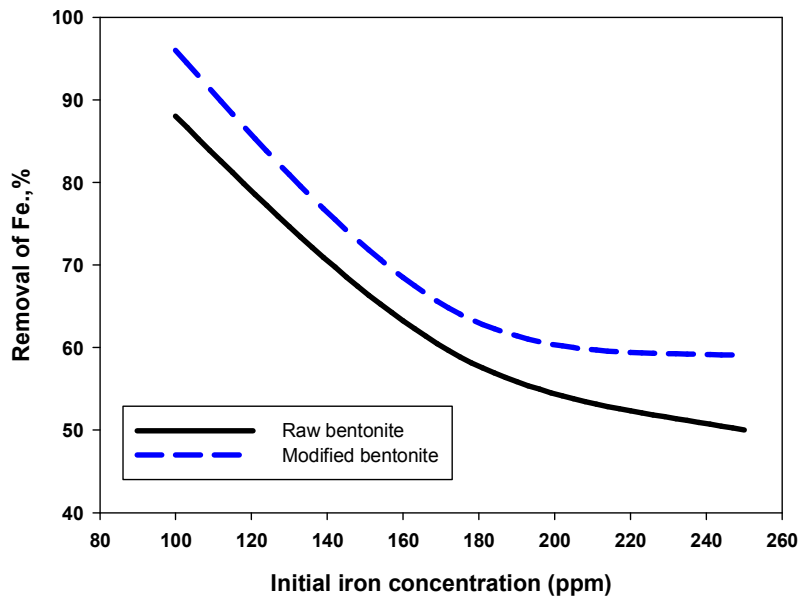

Figure 8. Differences in the removal of Fe., \% between natural and modified bentonite with initial concentration at the optimum time: 60 minute (PH:4, Dose : 0.6 ppm). 


\section{(iii). Interaction Between Bentonite Dose and Initial \\ Concentration}

The interaction between the initial concentration of iron and the amount of bentonite appears in the 3D diagram for raw and modified bentonite (Figure 9A and $\mathrm{B}$ ). The plotting process was performed at $\mathrm{pH} 4$ and central contact time of 60 min. At any given initial concentration for iron ions, there are increasing in the removal efficiency with increasing the applied dose from $0.2 \mathrm{~g}$ to $1 \mathrm{~g}$ either raw bentonite or modified bentonite. The interaction of bentonite dose at different initial concentrations can be explained after fixed central contact time of $60 \mathrm{~min}$ and applied dose $0.2 \mathrm{~g}$, where the removal efficiency for the raw bentonite decrease from $40.67 \%$ to $26.5 \%$ by increasing the initial concentration from $100 \mathrm{ppm}$ to $250 \mathrm{ppm}$. Under the same conditions, the removal value decreased from $50.74 \%$ to 35.21 for the treated bentonite. Thermally modified bentonite was found to be the best at all the given doses as illustrated in (Figure10).

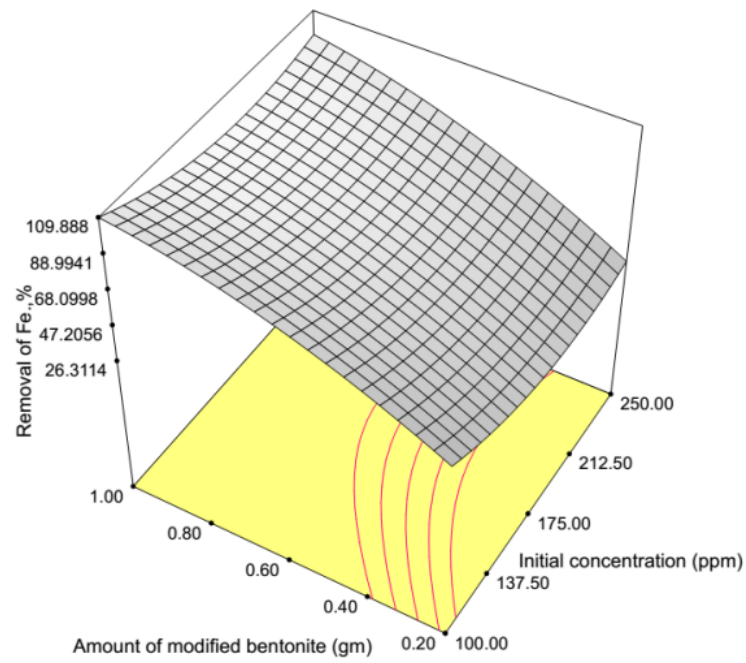

(A)

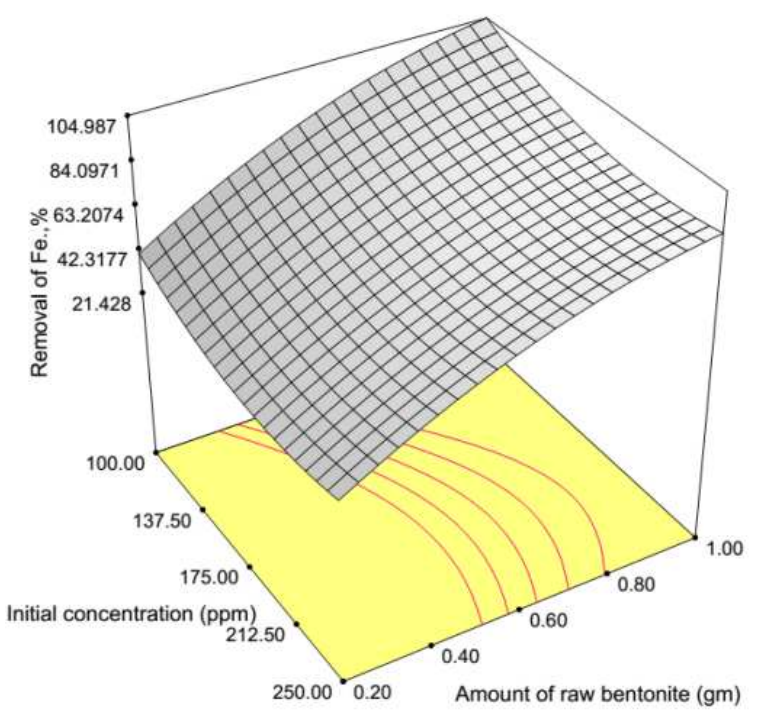

(B)

Figure 9. Interaction effect between contact time and initial iron concentration (A) Raw bentonite (B) Thermally modified bentonite.

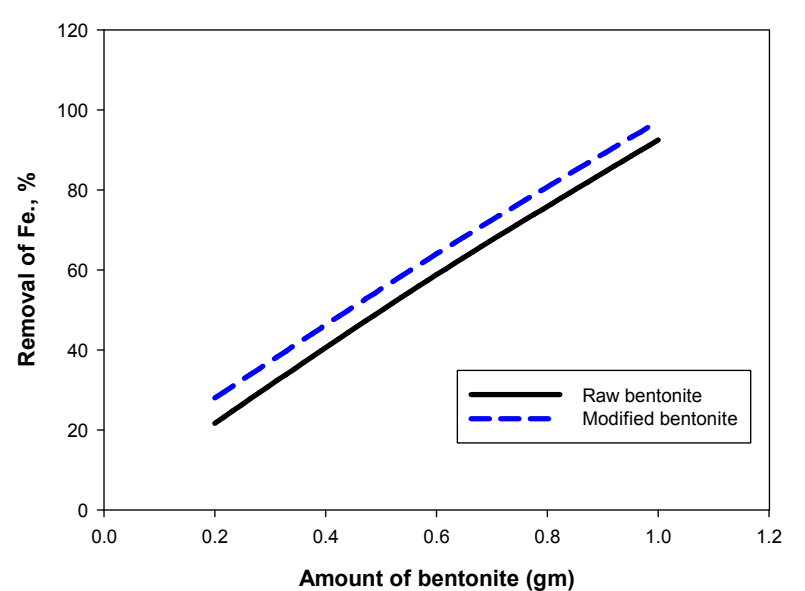

Figure 10. Differences in the removal of Fe., \% between natural and modified bentonite with dose at the optimum time: 60 minute (PH:4, initial concentration : $175 \mathrm{ppm} / \mathrm{L}$ ).

\section{Optimum Conditions}

Experimental results showed that $15 \mathrm{~min}$ of contact time, $100 \mathrm{mg} / \mathrm{L}$ of iron concentration in and $1 \mathrm{~g}$ of bentonite dose were the best conditions for the maximum removal of iron ions from solutions with values of $95 \%$ and $98 \%$ for the raw and treated bentonite, respectively. Taking advantage of the quadratic programming, the predicted optimum conditions for maximum iron removal by raw and thermally modified bentonite can be obtained using Design Expert's optimization function in terms of the upper and lower limits for the selected variables (contact time, initial concentrations and dose) for the both products. The predicted solutions for the optimum conditions for raw and modified bentonite samples with their predicted values were listed in (Table 3 and Table 4). From the tables, it is clear that the polynomial model can enhance the removal efficiency of iron by raw and thermally modified bentonite to percentages of $100 \%$ at lower concentrations of iron about $100 \mathrm{ppm}$. The predicted conditions and associated predicted removal values indicated that $0.8 \mathrm{~g}$ of thermally modified bentonite has the same quality produced by $0.96 \mathrm{~g}$ of raw bentonite. In addition, 50 min of contact time by using the modified bentonite gave the same results with the raw bentonite at shaking time of $60 \mathrm{~min}$

\section{Conclusion}

The studied natural Egyptian bentonite showed high efficiency in the removal of iron ions from water. By thermal treatment of the raw bentonite at $100^{\circ} \mathrm{C}$ for $1 \mathrm{~h}$, the removal efficiency increased due to increasing the specific surface area. Second order quadratic polynomial model was used in optimizing and modeling the effect of the selected parameters on the removal of iron by raw and thermally modified bentonite.

The predicted values from the regression mathematical equations which were obtained from the quadratic polynomial programming were highly correlated with the experimental results $\left(\mathrm{R}^{2}\right.$ values above 0.9$)$ for the required 
responses in both raw and thermally modified bentonite. Therefore, the resulted data was well fitted the model. 3D and linear graphs were used to understand the effect of variables and the interaction between them. The removal efficiency could be enhanced to $100 \%$ under the predicted conditions suggested by the quadratic programming indicating that the bentonite modified at $100^{\circ} \mathrm{C}$ is more promising.

Table 4. Predicted optimizes solutions for iron removal by raw bentonite.

\begin{tabular}{lllll}
\hline $\begin{array}{l}\text { Contact } \\
\text { time (min) }\end{array}$ & $\begin{array}{l}\text { Initial } \\
\text { concentrations } \\
\text { (ppm) }\end{array}$ & Dose (g) & $\begin{array}{l}\text { Removal } \\
\text { of iron \% }\end{array}$ & Desirability \\
\hline 60 & 108 & 0.96 & $100 \%$ & 1.00 \\
46 & 110 & 0.87 & $95.47 \%$ & 1.00 \\
44 & 111 & 0.92 & $96 \%$ & 1.00 \\
52.39 & 107.22 & 0.96 & 98.97 & 1.00 \\
\hline
\end{tabular}

Table 5. Predicted optimizes solutions for iron removal by treated bentonite.

\begin{tabular}{lllll}
\hline $\begin{array}{l}\text { Contact } \\
\text { time } \\
(\mathbf{m i n})\end{array}$ & $\begin{array}{l}\text { Initial } \\
\text { concentrations } \\
(\mathbf{p p m})\end{array}$ & Dose $(\mathbf{g})$ & $\begin{array}{l}\text { Removal } \\
\text { of iron \% }\end{array}$ & Desirability \\
\hline 57 & 107 & 0.81 & $99.47 \%$ & 1.00 \\
60 & 102 & 0.80 & $100 \%$ & 1.00 \\
50 & 100 & 0.96 & $100 \%$ & 1.00 \\
\hline
\end{tabular}

\section{References}

[1] B. Das, P. Hazarika, G. Saikia, H. Kalita, D. C. Goswami, H. B. Das, S. N. Dube, R. K. Dutta, Removal of iron from groundwater by ash: A systematic study of a traditional method, J. Hazard. Mater. 141 (2007) 834-841.

[2] Barlokova. D and Ilavsky. J, Research Paper Removal of Iron and Manganese from Water Using Filtration By Natural Materials. Of disposers J. Environ. Stud 19 (6), 2010, 11171122 .

[3] Ahmed, M. (2012) Iron and Manganese removal from groundwater. Master thesis to Department of Geosciences, Faculty of Mathematics and Natural Sciences, University of Oslo, p101.

[4] G. Gedge, Corrosion of cast Iron in potable water service, Proceedings of the Institute of Materials Conference. London, UK, 1992.

[5] G. J. Kontoghiorghes, E. D. Weinberg Iron, mammalian defense systems, mechanisms of disease, and chelation therapy approaches, Blood Rev. 9 (1995) 33-45.

[6] J. D. Zuane, Handbook of Drinking Water Quality, Van Nostrand Reinhold, New York, 1990.

[7] Ehssan, M. N. (2012) Utilization of Bentonite As an Adsorpent $\mathrm{m}$ /aterial in the removal of iron. International Journal of Engineering Science and Technology, 4, 4480-4489.

[8] Al-Anber, M. A. (2010) Removal of high-level Fe3+ from aqueous solution using natural inorganic materials: Bentonite (NB) and quartz (NQ). Desalination, 250, 885-891.

[9] Homoncik, S. C., MacDonald, A. M., Heal, K. V., Dochartaigh, B. E. O.”. \& Ngwenya, B. T. 2010. Manganese concentrations in Scottish groundwater. Science of the Total Environment, 408, 2467 ก 2473.
[10] Zamzow MJ, Murphy JE (1992) Removal of metal cations from water using zeolite. Sep Sci Technol 14: 1969-1984.

[11] G. Chen, Electrochemical technologies in wastewater treatment, Sep. Purif. Technol. 38 (1) (2004) 11-41.

[12] P. Sarin, V. L. Snoeyink, J. Bebee, K. K. Jim, M. A. Beckett, W. M. Kriven, J. A. Clement, Iron release from corroded iron pipes in drinking water distribution systems, Water Res. 38 (5) (2004) 1259-1269.

[13] World Health Organization.1996 Guidelines for drinking water quality. In Health criteria and other supporting information, vol. 2, 248-253, Geneva: world Health Organization.

[14] European Union. 1998. Richtlinie 98/83/EG des Rates.

[15] Ellis D. et al. (2000), "Removal of iron and manganese from groundwater by oxidation and microfiltration", Desalination, Vol. 130 , pp. 255-264.

[16] Shavandi M. A., Haddadian Z., Ismail M. H. S., Abdullah N., Abidin Z. Z., 2012, Removal of Fe(III), Mn(II) and Zn(II) from palm oil mill effluent (POME) by natural zeolite, Journal of the Taiwan Institute of Chemical Engineers, 43, 750-759.

[17] Cartwright, P. S., "Membranes Separations Technology for Industrial Effluent Treatment - A Review", Desalination, 56, 17 (1985).

[18] E. Erdem, N. Karapinar, R. Dona (2004) The removal of heavy metal cations by natural zeolites. Journal of Colloid and Interface Science, 280, 309-314.

[19] Schneider, A. R., Porter, E. T., and Baker, JE, 2007. Polychlorinated biphenyl release from resuspended Hudson River sediment. Environmental Science and Technology, Vol. 41, No.14: 1097-1103.

[20] Mohan S, Gandhimathi R (2009) Removal of heavy metal ions from municipal solid waste leachate using coal fly ash as an adsorbent. J Hazard Mater 169:351-359.

[21] Barbier F, Duc G, Petit-Ramel M (2000). Adsorption of lead and cadmium ions from aqueous solution to the montmorillonite/water interface Colloids Surfaces A: Physicochem. Eng. Aspects 166 (1-3):153-159.

[22] Brigatti, M. F., Corradini, F, Franchini, G. C., Mazzoni, S., Medici, L. \& Poppi L. (1995) - Interaction between montmorillonite and pollutants from industrial waste-waters: exchange of $\mathrm{Zn}^{2+}$ and $\mathrm{Pb}^{2+}$ from aqueous solutions. Applied Clay Science, 9, 383-395.

[23] J. S. Kim and M. A. Keane (2002) The removal of iron and cobalt from aqueous solutions by ion exchange with $\mathrm{Na}-\mathrm{Y}$ zeolite: batch, semi-batch and continuous operation. Journal of Chemical Technology and Biotechnology, 66, 633-640.

[24] Kaya A. and Ören A. H., 2005. Adsorption of zinc from aqueous solutions to the bentonite. J. Hazard. Mater., 125, 183-189.

[25] Doulia, D., Leodopoloud, C., Gimouhopoulos, K. and Rigas, F. 2009. Adsorption of humic acid on acidactivated Greek bentonite. Journal of Colloid and Interface Science. 340:131-141.

[26] Rauf, N., Tahir, S. S., 2000. Thermodynamics of Fe(II) and $\mathrm{Mn}$ (II) adsorption onto bentonite from aqueous solutions. J. Chem. Thermodynamics 32, 651-658. 
[27] Novak, I. and Cicel, B. (1978) Dissolution of Smectites in Hydrochloric Acid: II Dissolution Rate as a Function of Crystallochemical Composition. Clays and Clay Minerals, 26, 341-344.

[28] BoL G. M. (1986) The effect of various polymers and salts on borehole and cutting stability in water-base shale drilling fluids. Int. Ass. Drilling Contractors/Soc. Petrol. Engineers, Paper No. 14802.

[29] Babaki H, Salem A, Jafarizad A. Kinetic model for the isothermal activation of bentonite by sulfuric acid, Mater. Chem. Phys. 2008; 108:263-268.

[30] Thaemlitz CJ, Patel AD, Coffin G, Conn L (1999). 'New Environmentally Safe High-Temperature Water-Based Drilling-Fluid System'. SPE 37606, SPE/IADC Drilling Conference, Amsterdam, March 4-6, 1997 and SPE Drilling \& Completion, vol.14, No. 3, 185-189.

[31] Alemdaroglu, T., G. Akkus, M. Onal, and Y. Sarikaya. 2003. Investigation of the surface acidity of a bentonite modified by acid activation and thermal treatment. Turk. J. Chem. 27: 675681 .

[32] Steudel, A., Batenburg, L. F., Fischer, H. R., Weidler, P. G., Emmerich, K. (2009) Alteration of swelling clay minerals by acid activation. Applied Clay Science, 44, 105, 115.

[33] Al-Asheh, S., Banat, F., Abu Aitah, L., (2003) Adsorption of phenol using different types of activated bentonite. Separation and Purification Technology, 33, 1-10.

[34] Toor, M. (2012) Enhancing Adsorption Capacity of Bentonite for dye removal: Physicochemical modification and Characterization. Master thesis to Department of Geosciences, Faculty of Mathematics and Natural Sciences, University of Oslo, p101.

[35] Ozcan, A., Omeroglu, C., Erdogan, Y., Ozcan, A. S. (2007) Modification of bentonite with a cationic surfactant: an adsorption study of textile dye Reactive Blue 19. J. Hazard. Mater., 140(1-2), 173-179.

[36] Myers, R. H. and Montgomery, D. C (2002) Response Surface Methodology. John Wiley and Sons, USA.

[37] Nuran, B. (2007) The Response Surface Methodology, Master of Science in Applied Mathematics and Computer Science, $\mathrm{Ph}$ D Dissertation, Faculty of the Indiana University South Bend.

[38] Ravikumar, K., Krishnan, S., Ramalingam, S. and Balu, K. (2007) Optimization of process variables by the application of response surface methodology for dye removal using a novel adsorbent. Dyes and Pigments, 72, 66-74, 2007.
[39] Xing-dong, L., Yi-pin, W., Xue-min, C., Yan, H. and Jin, M. (2013) Influence of synthesis parameters on $\mathrm{NaA}$ zeolite crystal. Powder Technology, 243, 184-193.

[40] Cilliers, J. J., Austin, R. C. and Tucker, J. P. (1992) An evaluation of formal experimental design procedures for hydrocyclone modeling. Proceeding 4th International Conference on Hydrocyclones, Southampton, 3-49.

[41] kandeel S H. 1989. Bentonite in Arab republic of Egypt. Public Authority of industrialization, Egypt.

[42] Tahoun S A, E A El-Naka, M El-Tohamy and M El-Fahham. 2005. El-Fayoum bentonite: from brick and ceramic industry to agricultural production. The 3rd International Conference Soils of Urban Industrial, Traffic, Mining and Military Areas. Available at: http://193.227.1.53/suitma/index.php.

[43] Abdel-Motelib, A., Abdel Kader, Z., Ragab, Y. A., Mosalamy, M. (2011) Suitability of a Miocene bentonite from North Western Desert of Egypt for pharmaceutical use. Applied Clay Science, 52, 140-144.

[44] Beragaya, F., Theng, B. K. G., Lagaly, G. (2006) Modified clay and clay minerals, Hand book of clay science, Development in clay science, Vol 1, El Siever, The Netherlands.

[45] Chorom, M., Rengasamy, P. (1996) Effect of heating on swelling and dispersion of different cationic forms on smectite. Clay and clay minerals, 44, 783-790.

[46] Rajasimman, M. and Murugaiyan, K. (2012) Application of the Statistical Design for the Sorption of Lead by Hypnea valentiae. Journal of Advanced Chemical Engineering, 2, 1-7.

[47] Deepa, C. N., Sayed, A. and Suresha, S. (2014) Kinrtic and isothermal studies on the removal of copper (П) from aqueous solution by Araucaria cook П: Response Surface Methodology for the the optimization. International Journal of Recent Scientific Research, 5, 820-827.

[48] Ramakrishnaiah, C. R. and Vismitha. (2012) Removal of Phosphate from Waste Water Using low-Cost Adsorbents. International Journal of Engineering Inventions, 1, 44-50.

[49] Mall, D. I., Srivastava, V. C. and Agarwal, N. K. (2006) Removal of Orange- $G$ and methyl violet dyes by adsorption onto bagasse fly ash-kinetic study and equilibrium isotherm analyses. Dyes and Pigments, 69, 210-223.

[50] Hamdi, N. and Srasra, E. (2012) Removal of phosphate ions from aqueous solution using Tunisian clays minerals and synthetic zeolite. Journal of Environmental Sciences, 24, 617623. 